\title{
Fine mapping of the $B n U C 2$ locus related to leaf up-curling and plant semi-dwarfing in Brassica napus
}

Chengwei Huang ${ }^{1 \dagger}$, Mao Yang ${ }^{1 \dagger}$, Danlei Shao ${ }^{1}$, Yangming Wang ${ }^{1}$, Shubei Wan ${ }^{1}$, Jianbo He ${ }^{1}$, Zuqing Meng ${ }^{2}$ and Rongzhan Guan ${ }^{1 *}$ (D)

\begin{abstract}
Background: Studies of leaf shape development and plant stature have made important contributions to the fields of plant breeding and developmental biology. The optimization of leaf morphology and plant height to improve lodging resistance and photosynthetic efficiency, increase planting density and yield, and facilitate mechanized harvesting is a desirable goal in Brassica napus.
\end{abstract}

Results: Here, we investigated a B. napus germplasm resource exhibiting up-curled leaves and a semi-dwarf stature. In progeny populations derived from NJAU5737 and Zhongshuang 11 (ZS11), we found that the up-curled leaf trait was controlled by a dominant locus, BnUC2. We then fine mapped the BnUC2 locus onto an 83.19-kb interval on chromosome A05 using single nucleotide polymorphism (SNP) and simple sequence repeat (SSR) markers. We further determined that BnUC2 was a major plant height QTL that explained approximately $70 \%$ of the phenotypic variation in two $\mathrm{BC}_{5} \mathrm{~F}_{3}$ family populations derived from NJAU5737 and ZS11. This result implies that BnUC2 was also responsible for the observed semi-dwarf stature. The fine mapping interval of BnUC2 contained five genes, two of which, BnaA05916700D (BnaA05.IAA2) and BnaA05916720D, were revealed by comparative sequencing to be mutated in NJAU5737. This result suggests that the candidate gene mutation (BnaA05g16700D, encoding Aux/IAA2 proteins) in the conserved Degron motif GWPPV (P63S) was responsible for the BnUC2 locus. In addition, investigation of agronomic traits in a segregated population indicated that plant height, main inflorescence length, and branching height were significantly reduced by $B n U C 2$, whereas yield was not significantly altered. The determination of the photosynthetic efficiency showed that the BnUC2 locus was beneficial to improve the photosynthetic efficiency. Our findings may provide an effective foundation for plant type breeding in B. napus.

Conclusions: Using SNP and SSR markers, a dominant locus (BnUC2) related to up-curled leaves and semi-dwarf stature in B. napus has been fine mapped onto an 83.19-kb interval of chromosome A05 containing five genes. The BnaA05.IAA2 is inferred to be the candidate gene responsible for the BnUC2 locus.

Keywords: Brassica napus, Up-curled leaves, Semi-dwarf, Single nucleotide polymorphism, Simple sequence repeat, Gene mapping

\footnotetext{
* Correspondence: guanrzh@njau.edu.cn

${ }^{\dagger}$ Chengwei Huang and Mao Yang contributed equally to this work.

${ }^{1}$ National Key Laboratory of Crop Genetics and Germplasm Enhancement,

Jiangsu Collaborative Innovation Center for Modern Crop Production,

Nanjing Agricultural University, Nanjing 210095, China

Full list of author information is available at the end of the article
}

C The Author(s). 2020 Open Access This article is licensed under a Creative Commons Attribution 4.0 International License, which permits use, sharing, adaptation, distribution and reproduction in any medium or format, as long as you give appropriate credit to the original author(s) and the source, provide a link to the Creative Commons licence, and indicate if changes were made. The images or other third party material in this article are included in the article's Creative Commons licence, unless indicated otherwise in a credit line to the material. If material is not included in the article's Creative Commons licence and your intended use is not permitted by statutory regulation or exceeds the permitted use, you will need to obtain permission directly from the copyright holder. To view a copy of this licence, visit http://creativecommons.org/licenses/by/4.0/ The Creative Commons Public Domain Dedication waiver (http://creativecommons.org/publicdomain/zero/1.0/) applies to the data made available in this article, unless otherwise stated in a credit line to the data. 


\section{Background}

Leaf morphology and plant stature are determining factors for dicot plant photosynthesis, dry mater accumulation, lodging resistance, tolerance to high planting density, and amenability to mechanized harvesting. Slight up-curling of leaves and a semi-dwarf stature may improve grain yield $[1,2]$. Research on leaf morphology and plant stature is important in the fields of plant developmental biology and crop genetic improvement. Leaf development from the shoot apical meristem comprises several stages, including leaf primordium formation, polarity establishment, and cell differentiation. Leaf curling is due to abnormal leaf development caused by mutations of genes related to leaf development [3-5]. Many genes have been identified to be involved in leaf development. Transcription factors, including KANADI [6-9], Class III HOMEODOMAIN LEUCINE-ZIPPER (HDZip III) [10-13], WUSCHEL RELATED HOMEOBOX (WOX) [14], and TB1-CYC-PCFs (TCPs) [15], participate in alteration of leaf polarity establishment, which leads to the up-curled leaf phenotype. Plant hormone biosynthesis and signal transduction is another major aspect that influences leaf shape. AUXIN/INDOLE-3ACETIC ACID (Aux/IAA) gene family mutations have been reported to cause leaf curling in plants [16-19]. The activity of auxin response factors (ARFs) affects the mutual antagonism between HD-ZIP IIIs and KANADI that regulates leaf development. Mutation of Arabidopsis $A R F 3$ can cause leaf curling [20]. The UCU1 gene encoding the SHAGGY/GSK3 protein involved in the signal transduction of auxin and BR can lead to downcurled leaves and short stature phenotypes [21]. In addition, some microRNAs that can specifically recognize the START domain of HD-ZIP III family genes, such as miRNA165 and miRNA166, may cause leaf curling by regulating HD-ZIP III family gene expression [11, 22-24]. miRNA160 regulates leaf curling by controlling the expressions of auxin-responsive genes ARF10 and ARF17 [25, 26]. miRNA164 affects the development of leaf margins by regulating the expression of the CUC1 gene, which may lead to a curled leaf phenotype [27].

Plant height is mainly determined by plant hormone biosynthesis, signal transduction, and related pathways. Although not described here, a well-documented relationship exists between the regulation of plant dwarf stature and genes involved in gibberellin and brassinosteroid biosynthesis and signal transduction pathways [28-33]. Auxin biosynthesis, polar transport, and signal transduction exert a crucial role in plant growth and development, including plant height determination. YUCCA encodes a flavin monooxygenase, a catalytic enzyme in the auxin biosynthesis pathway, and mutation of YUCCA leads to short stature in plants $[34,35]$.
Phosphorylated glycoproteins PGP1 and PGP19/MDR1 are vectors for auxin transport. Because of their weaker auxin polar transport capacities, the $m d r 1-1$ single mutant and mdr1-1/pgp1-1 double mutant of Arabidopsis are dwarfs [36, 37]. The auxin signal transduction pathway is mainly composed of transport inhibitor resistant1/auxin signaling F-box proteins (TIR1/AFBs), Aux/ IAA proteins, and ARFs [38-40]. Aux/IAA proteins, which act as repressors of auxin-regulated transcriptional activation, possess four conserved domains (domains I, II, III, and IV), and domain II contains a strongly conserved amino acid motif, GWPPV. In the presence of auxin, TIR1/AFBs can recognize this motif and bind to the Aux/IAA proteins, leading to the degradation of Aux/IAA proteins. ARF is then released to activate the expressions of auxin-response genes [41, 42]. The GWPPV motif, called the Degron domain, is thus the core component of auxin signal transduction [43-46]. Mutations of any sequence in the GWPPV motif or its flanks can lead to defective plant growth and development, including the generation of shorter hypocotyls and stature, leaf curling, reduction in the number of lateral roots, and loss of apical dominance [47-49]. In Arabidopsis and B. napus, mutations of Aux/IAA genes decrease plant height and lead to leaf curling [17, 5052].

Curled-leaf traits, including up-curling, down-curling, and wrinkling, are often observed in B. napus. Leaf upcurling is a useful trait that allows an increase in the planting density of $B$. napus. Published research on curled-leaf traits is limited. Wang et al. [53] found that the wrinkled, down-curved leaf type of $B n d w f / d c l l$, which is short-statured, is controlled by a dominant gene. Li et al. [51] reported a B. napus mutant, sca, with crinkled leaves, a semi-dwarf stature, narrow branch angles, and upright siliques, and determined that the underlying gene related to the mutated traits is a semidominant gene. Zhao et al. [17] discovered that a semidominant gene is responsible for an extremely dwarf mutant, $d s-4$, with down-curved leaves. Yang et al. [54] uncovered an up-curling leaf locus (BnUC1) associated with a dominant gene.

Because of the important role of dwarf/semi-dwarf plant resources in crop genetic improvement, especially in dicots, their excavation and utilization has attracted the attention of agronomists and biologists. In B. napus, the dwarf phenotypes of $b z h$ [55] and NDF-1 [56] mutants are controlled by a major gene with additive effects, while the dwarf trait of 99CDAM [57] is caused by three pairs of recessive genes. Although some mutants related to plant height in B. napus have been reported, few genes have been studied to clarify their mechanical roles in plant development. The semi-dwarf nature of gibberellin-insensitive mutants, including NDF-1 [56], 
$d s-1$ [58], ds-3 [59] and banC.dwf [60], and $d s-1$ and $d s-$ 3 are caused by a mutation in the VHYNP motif of the DELLA protein. In $d s-4$ [17] and sca [51] mutants insensitive to auxin, a mutation in the GWPPV motif of the Aux/IAA7 protein is responsible for their semi-dwarf/dwarf phenotypes. The dwarf characteristics of banC.dwf [60], Bndwf1 [61] and Bndwf/dcl1 [53] are controlled by a pair of dominant genes, while those of $d s-1$ [58], $d s-3$ [59], $d s-4$ [17] and sca [51] are regulated by a single semi-dominant ones. Many dwarfing genes have a negative effect on crop agronomic traits, which restricts the breeding development of dwarf or semi-dwarf varieties [62]. The investigation of dwarf mutants, the identification of new dwarfing genes, and the elucidation of dwarfing mechanisms are therefore crucial for genetic improvement of B. napus.

In the present study, we investigated the pure $B$. napus line NJAU5737 (named Bnuc2), a new semidwarf mutant with up-curled leaves developed in our laboratory, analyzed the inheritance of the up-curled leaf trait, and fine mapped the $B n U C 2$ locus. We also evaluated the effects of the $B n U C 2$ locus on agronomic traits. Our results may provide an effective foundation for plant type breeding in B. napus. Our findings may also serve as a foundation for the semidwarf variety breeding of $B$. napus and exploration of the dwarfing mechanism.

\section{Results}

Performance of the up-curled-leaf mutant

Compared with the Zhongshuang11 (ZS11), the NJAU5737 had shorter hypocotyls and stature. In addition, leaves of NJAU5737 were up-curled and slightly crinkled, whereas ZS11 had normal, flat leaves (Fig. 1a, b). At the mature stage, NJAU5737 plants were approximately $120-130 \mathrm{~cm}$ high. $\mathrm{F}_{1}$ seedlings of NJAU5737 $\times$ ZS11 had up-curled, crinkled leaves (Fig. $1 \mathrm{a}, \mathrm{b})$, with mature plant heights that were intermediate between those of the two parents (Fig. 1c).

The leaf $\mathrm{Chl} \mathrm{a}, \mathrm{Chl} \mathrm{b}$, and total Chl contents and $\mathrm{Chl} \mathrm{a} / \mathrm{b}$ ratio in up-curled leaves were significantly higher than flat leaves at the seedling stage (Table 1). This result indicated that the up-curled leaf trait was associated with elevating the leaf Chl content, and result in deep-green leaves.

The leaf net photosynthetic rate, stomatal conductance and concentration of intercellular $\mathrm{CO}_{2}$ of up-curled leaves were significantly higher than those of flat leaves at the seedling stage, and there was no significant difference in the leaf transpiration rate between the two leaf morphology pattern (Table 2). These results imply that the up-curled leaf trait is associated with elevating the photosynthetic efficiency.

\section{Inheritance of the up-curled leaf trait}

Plants in $F_{1}\left(Z S 11 \times\right.$ NJAU5737) and RF $_{1}($ NJAU5737 $\times$ ZS11) generations, obtained by crossing NJAU5737 (up-

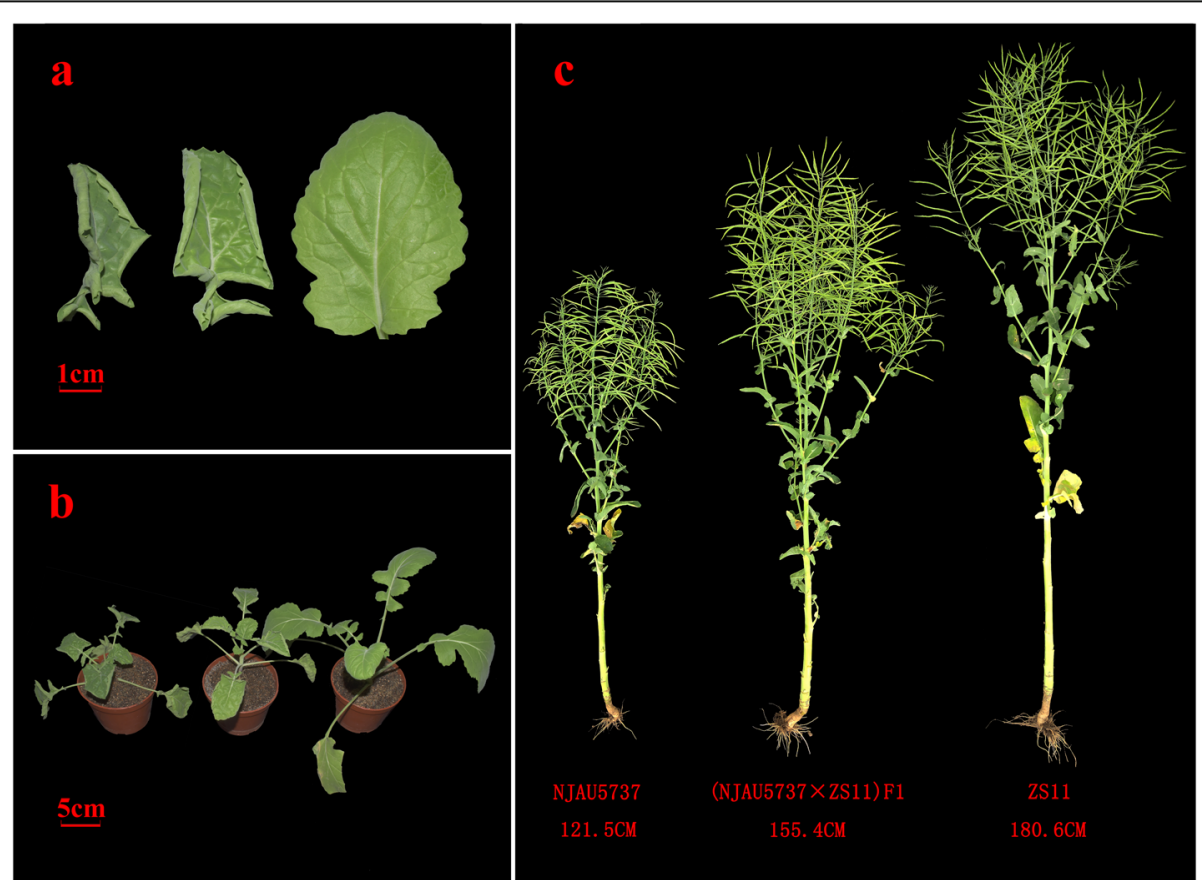

Fig. 1 Performance of NJAU5737, (NJAU5737 $\times$ ZS11) F1 and ZS11. a Leaf of NJAU5737 (left), (NJAU5737 $\times$ ZS11) $F_{1}$ (middle) and ZS11 (right) at the seedling stage. b Seedling of NJAU5737 (left), (NJAU5737 $\times$ ZS11) $F_{1}$ (middle) and ZS11 (right). c NJAU5737 (left), (NJAU5737 $\times$ ZS11) $F_{1}$ (middle) and ZS11 (right) at mature stage 
Table 1 Leaf chlorophyll contents of up-curled leaf and flat leaf in $\mathrm{BC}_{5} \mathrm{~F}_{3}$ population

\begin{tabular}{lllll}
\hline Phenotype & Chl a content $(\mathrm{mg} / \mathrm{g})$ & Chl b content $(\mathrm{mg} / \mathrm{g})$ & Total Chl content $(\mathrm{mg} / \mathrm{g})$ & Chl a/b ratio \\
\hline Up-curled leaf & $1.37 \pm 0.15^{* *}$ & $0.47 \pm 0.01^{* *}$ & $1.83 \pm 0.15^{* *}$ & $2.94 \pm 0.36^{* *}$ \\
Flat leaf & $1.15 \pm 0.12$ & $0.43 \pm 0.02$ & $1.58 \pm 0.12$ & $2.69 \pm 0.27$
\end{tabular}

**indicates significant at the 0.01 probability level. Mean \pm standard deviation $(S D)$ under sample size

curled leaves) with ZS11 (normal, flat leaves), all possessed up-curled leaves, which implies that the leafcurling trait is controlled by dominant genes. The segregation ratio of up-curled to normal leaves in all obtained backcross populations with a dominant locus, from $\mathrm{BC}_{1}$ to $\mathrm{BC}_{6}$ to $\mathrm{ZS11}$, was in good agreement with the expected Mendelian segregation ratio of 1:1 according to Chi-square tests (Table 3). Furthermore, segregation in subsequently selfed $\mathrm{BC}_{5} \mathrm{~F}_{2}$ family populations and two $\mathrm{BC}_{5} \mathrm{~F}_{3}$ populations was in accord with the expected Mendelian segregation ratio of 3:1 (up-curled vs. normal leaves) (Table 3). These results indicate that leaf upcurling is controlled by a dominant locus (BnUC2).

\section{Genetic mapping of the BnUC2 locus}

Eight plants with up-curled leaves from the consecutive backcross $\mathrm{BC}_{5}$ family population were genotyped along with the two parents, NJAU5737 and ZS11, using a Brassica $60 \mathrm{~K}$ SNP bead chip array (Illumina, US). The SNP chip data analysis uncovered a $\mathrm{BC}_{5}$ plant (named BnUC2-5) with three segments, on chromosomes A05, $\mathrm{C} 02$, and $\mathrm{C07}$, that differed from those in the recurrent parent ZS11 (Additional file 1: Table S1). The A05 differential segment contained 227 polymorphic SNP markers covering a $6.05-\mathrm{Mb}$ interval between SNP markers M10447 and M11106. The C02 differential segment included 198 polymorphic SNP markers encompassing a 3.81-Mb interval between SNP markers M25019 and M36509, and the C07 differential segment harbored 231 polymorphic SNP markers covering an interval of $4.17 \mathrm{Mb}$ between SNP markers M34819 and M44556. These three segments were possible candidate regions harboring the $B n U C 2$ locus. As other plants had larger genomic disparities than BnUC2-5, the latter plant was selfed and backcrossed to build populations for mapping of the up-curled leaf locus. As a result, 286 $\mathrm{BC}_{5} \mathrm{~F}_{2}$ individuals and $246 \mathrm{BC}_{6}$ individuals were obtained. Using these plants, 60 SSR-marker primer pairs were designed on the basis of the genomic sequences of the three differential segments. In SSR experiments, six polymorphic co-dominant SSR markers (BnaC02-12, BnaC02-14, BnaC07-04, BnaC07-05, BnaA05-21, and BnaA05-25) were found on the three segments.

All plants in $\mathrm{BC}_{6}$ and $\mathrm{BC}_{5} \mathrm{~F}_{2}$ family populations were analyzed using the six polymorphic markers. Calculations of recombination frequencies in JoinMap 4.1 based on the resulting data suggested that the $B n U C 2$ locus was located on the A05 differential segment.

Next, 70 SSR primer pairs were designed to map the $B n U C 2$ locus on the A05 chromosome. Five of these markers (BnaA05-121, BnaA05-127, BnaA05-133, BnaA05-256, and BnaA05-23) were found to be polymorphic (Additional file 2: Table S2). To construct linkage maps containing the up-curled-leaf trait locus $B n U C 2$ (Fig. 2a), $246 \mathrm{BC}_{6}$ and $286 \mathrm{BC}_{5} \mathrm{~F}_{2}$ plants were genotyped with the five polymorphic markers. A linkage map including the BnUC2 locus was then generated in JoinMap 4.1 and used to localize the $B n U C 2$ locus to a $3.84-\mathrm{Mb}$ interval between SSR markers BnaA05-133 and BnaA05-256. The arrangement of the markers on the linkage map was in good agreement with the physical genome map of B. napus, thus indicating that this preliminary mapping was reliable.

To fine map the $B n U C 2$ locus, $1661 \mathrm{BC}_{5} \mathrm{~F}_{3}$ plants were obtained by selfing $\mathrm{BC}_{5} \mathrm{~F}_{2}$ non-recombinant plants heterozygous at the BnUC2 locus according to SSR marker analysis. In addition, we designed 160 SSR primers within the preliminary mapping interval, 10 of which were found to be polymorphic (BnaA05-385, BnaA05336, BnaA05-442, BnaA05-730, BnaA05-364, BnaA05375, BnaA05-347, BnaA05-343, BnaA05-94, and BnaA05-90) (Additional file 2: Table S2). Next, the 1661 $\mathrm{BC}_{5} \mathrm{~F}_{3}$ plants were scanned with polymorphic markers, and linkage maps were obtained using JoinMap 4.1 (Fig. $2 \mathrm{~b})$. Finally, the BnUC2 locus was mapped onto the interval between SSR markers BnaA05-730 and BnaA05-336, with marker BnaA05-442 found to be cosegregated with the $B n U C 2$ locus as shown by distinct SSR bands (Fig. 3). The frequency of recombination between BnaA05-730 and BnaA05-336 was 0.06\%, and the mapping interval was $83.19 \mathrm{~kb}$ long. No other

Table 2 Leaf photosynthetic indicators of up-curled leaf and flat leaf in $\mathrm{BC}_{5} \mathrm{~F}_{3}$ population

\begin{tabular}{lllll}
\hline Phenotype & $\mathrm{NPR} \mathrm{\mu mol} \mathrm{CO} \mathrm{m}^{-2} \mathrm{~s}^{-1}$ & $\mathrm{SC} \mathrm{mol} \mathrm{H} \mathrm{O} \mathrm{m}^{-2} \mathrm{~s}^{-1}$ & $\mathrm{ICC} \mu \mathrm{mol} \mathrm{CO}_{2} \mathrm{~mol}^{-1}$ & $\mathrm{TR} \mathrm{mmol} \mathrm{H}_{2} \mathrm{O} \mathrm{m} \mathrm{m}^{-2}$ \\
\hline Up-curled leaf & $12.18 \pm 0.78^{* *}$ & $0.34 \pm 0.02^{* *}$ & $398.50 \pm 6.37^{* *}$ & $2.89 \pm 0.37$ \\
Flat leaf & $9.67 \pm 0.51$ & $0.22 \pm 0.03$ & $368.36 \pm 4.89$ & $2.30 \pm 0.36$ \\
\hline
\end{tabular}

Data are presented as means $\pm S D, n=6 .{ }^{* *}$ indicates significant at 0.01 probability level. NPR, SC, ICC and TR denote net photosynthetic rate, stomatal conductance, intercellular $\mathrm{CO}_{2}$ concentration and transpiration rate, respectively 
Table 3 Genetic segregation analysis of BnUC2 in populations derived from NJAU5737 and the recurrent parent ZS11 in Brassica napus

\begin{tabular}{llllll}
\hline Population & Up-curled leaf & Flat leaf & Total & Expected ratio & $x^{2}$ value \\
\hline $\mathrm{F}_{1}$ & 120 & 0 & 120 & & \\
$\mathrm{RF}_{1}$ & 115 & 0 & 115 & & \\
$\mathrm{BC}_{1}$ & 60 & 55 & 115 & $1: 1$ & 0.22 \\
$\mathrm{BC}_{2}$ & 42 & 56 & 98 & $1: 1$ & 2.00 \\
$\mathrm{BC}_{3}$ & 45 & 57 & 102 & $1: 1$ & 1.41 \\
$\mathrm{BC}_{4}$ & 58 & 70 & 128 & $1: 1$ & 1.13 \\
$\mathrm{BC}_{5}$ & 40 & 48 & 88 & $1: 1$ & 0.73 \\
$\mathrm{BC}_{6}$ & 127 & 119 & 246 & $1: 1$ & 0.26 \\
$\mathrm{BC}_{5} \mathrm{~F}_{2}$ & 211 & 75 & 286 & $3: 1$ & 0.23 \\
$\mathrm{BC}_{5} \mathrm{~F}_{3}(1)$ & 641 & 227 & 868 & $3: 1$ & 0.61 \\
$\mathrm{BC}_{5} \mathrm{~F}_{3}(2)$ & 588 & 205 & 793 & $3: 1$ & 0.31 \\
\hline
\end{tabular}

polymorphic marker was detected in the mapping interval. The order was completely consistent with the physical genome map of B. napus (Fig. 2c). These results verified the quality of the mapping.

\section{Effect of the BnUC2 locus on plant height}

To evaluate the effect of the $B n U C 2$ locus on plant height, all plants in the two $\mathrm{BC}_{5} \mathrm{~F}_{3}$ family populations were genotyped with the co-dominant SSR marker
BnaA05-442 co-segregating with $B n U C 2$, and their heights were measured.

Analysis of variance (ANOVA) uncovered extremely significant variation with respect to the three markergenotypes of BnaA05-442 co-segregating with leaf shape phenotype in the $\mathrm{BC}_{5} \mathrm{~F}_{3}$ (1) and $\mathrm{BC}_{5} \mathrm{~F}_{3}$ (2) populations (Table 4). This result clearly indicated that the $B n U C 2$ locus affects plant height.

The effect of $B n U C 2$ genotype on average plant height was assessed in the $\mathrm{BC}_{5} \mathrm{~F}_{3}(1)$ and $\mathrm{BC}_{5} \mathrm{~F}_{3}$ (2) populations (Table 5). Compared with the heights of homozygous plants having normal, flat leaves, the average height of homozygous plants with up-curled leaves was reduced by 28.86 and $28.93 \%$ in $\mathrm{BC}_{5} \mathrm{~F}_{3}(1)$ and $\mathrm{BC}_{5} \mathrm{~F}_{3}$ (2) populations, respectively. These differences were extremely significant. Plant heights were also significantly lower in heterozygous plants with up-curled leaves, with reductions of 14.15 and $12.50 \%$ in $\mathrm{BC}_{5} \mathrm{~F}_{3}$ (1) and $\mathrm{BC}_{5} \mathrm{~F}_{3}$ (2) populations, respectively. We thus concluded that the $B n U C 2$ locus has a negative effect on plant height.

On the basis of these results, we concluded that the $B n U C 2$ locus not only controls leaf type, but also controls plant height, leading to a semi-dwarf phenotype. By regarding the $B n U C 2$ locus as a quantitative trait locus (QTL) for plant height, we were able to calculate its role. According to analysis of data from the $\mathrm{BC}_{5} \mathrm{~F}_{3}$ (1) and $\mathrm{BC}_{5} \mathrm{~F}_{3}(2)$ populations, the effect of the QTL was mainly additive (Table 5). The BnUC2 locus explained 72.72

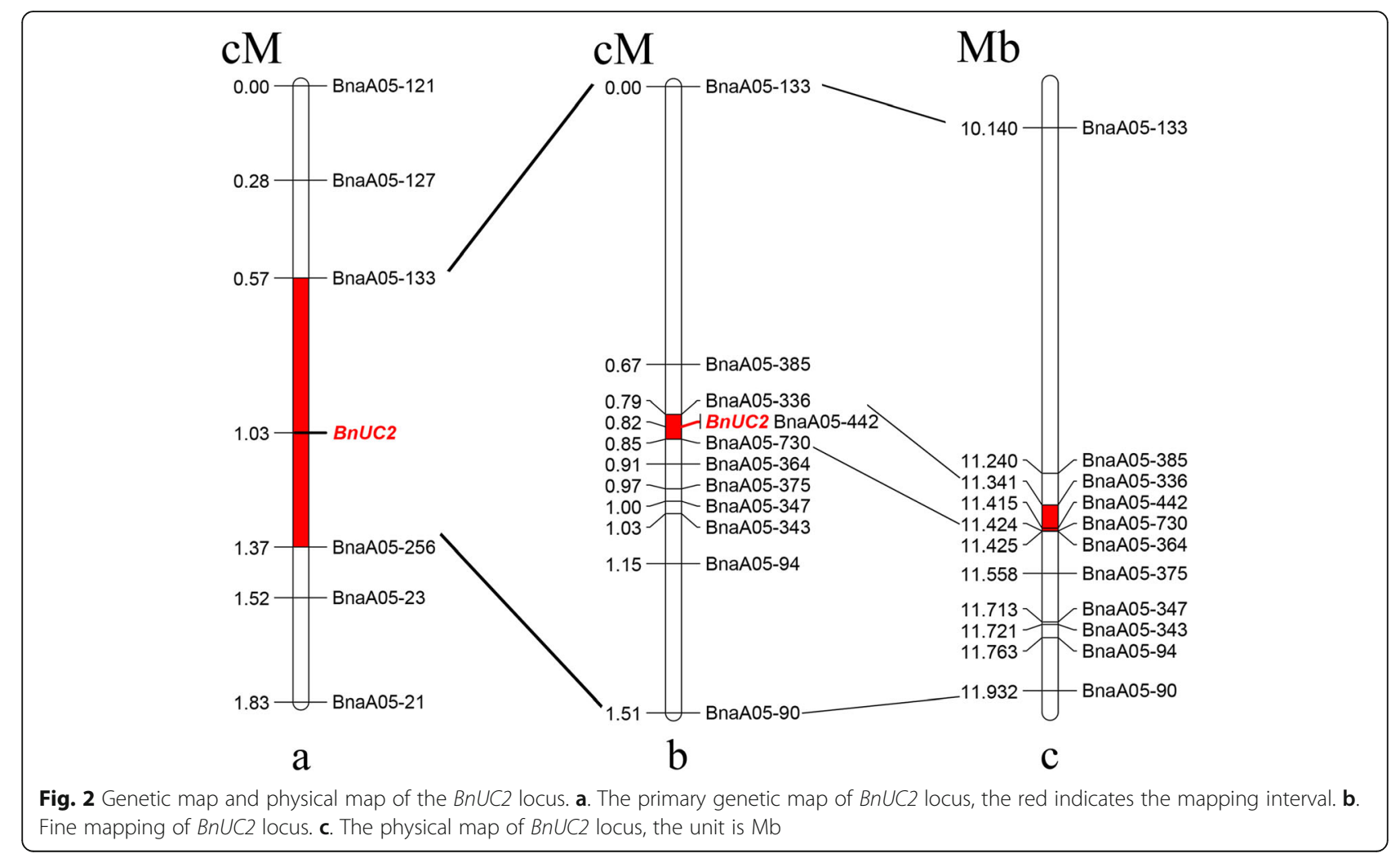




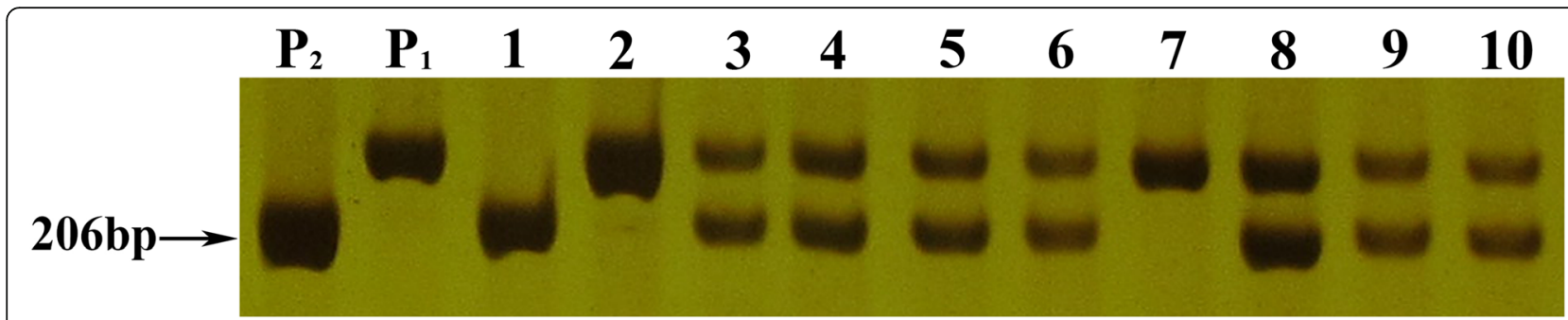

Fig. 3 Experimental results of polymorphic marker BnaA05-442. Marker scan with progeny $\mathrm{BC}_{5} \mathrm{~F}_{3}$ populations derived from the parents $\mathrm{ZS} 11$ and NJAU5737 was conducted. $P_{1}$ and $P_{2}$ indicates PCR products from the parents ZS11 and NJAU5737 plants, respectively. The number 3, 4, 5, 6, 8, 9 and 10 denote the PCR products from heterozygous plants with up-curled leaves, and 1 denotes the PCR products from homozygous plants with up-curled leaves, and 2 and 7 denote the PCR products from homozygous plants with flat leaves. Full-length, original blots image was presented in additional file 6: Fig. S3

and $70.41 \%$ of phenotypic variation in plant height in the $\mathrm{BC}_{5} \mathrm{~F}_{3}$ (1) and $\mathrm{BC}_{5} \mathrm{~F}_{3}$ (2) populations, respectively. Frequency distributions in the two family populations were also analyzed (Additional file 3: Fig. S1). Based on polygene hypothesis in quantitative genetics [63], plant heights were not normally distributed but instead followed a multimodal distribution, consistent with the effect of a major gene. We thus concluded that the $B n U C 2$ locus is a major QTL for plant height.

\section{Candidate gene analysis}

Using the B. napus Genome Browser (http://www.genoscope.cns.fr/brassicanapus/), five genes were identified and annotated in the fine mapping interval (Table 6). Two of these genes, BnaA05g16680D and BnaA05g16700D, are homologous to AT3G23050.1 and AT3G23030.1 found in the Arabidopsis Information Resource database that encode Aux/IAA7 and Aux/IAA2 proteins, respectively. These two Arabidopsis Aux/IAA proteins, which have been reported to act as repressors of auxin-regulated transcriptional activation, have four conserved domains (domains I, II, III, and IV) [41]. At high auxin concentrations, TIR1 interacts with Aux/IAA proteins via domain II to activate the degradation of Aux/IAA proteins by $26 \mathrm{~S}$ proteasome, with ARFs then released [64]. Mutations of Aux/ IAA family genes can lead to defective plant growth and development, including the generation of shorter hypocotyls and stature, leaf curling, reduction in lateral root number, and loss of apical dominance [17, 47, 48, 65-67]. BnaA05g16680D and BnaA05g16700D were thus considered to be candidate genes responsible for leaf up-curling and plant semi-dwarfing.

BnaA05g16690D in the mapping interval encodes an unknown protein, while BnaA05g16710D is homologous to AT3G23020.1, which encodes a tetratricopeptide repeat (TPR)-like superfamily protein. BnaA05g16690D and BnaA05g16710D have no previously reported relationship to leaf type and plant height regulation.

BnaA05g16720D is homologous to AT3G23000.1, which encodes a CBL interaction protein kinase 7 (CIPK7). CIPK7 is involved in the regulation of plant adversity stress and participates in plant signal transduction during response to abiotic stress conditions $[68,69]$. No association has been reported between BnaA05g16720D and the regulation of leaf type and plant height.

To further assess the above gene candidates for the $B n U C 2$ locus, we performed comparative sequencing of NJAU5737 and ZS11, the parents of the mapping populations. The DNA sequences of BnaA05g16680D, BnaA05g16690D, and BnaA05g16710D were identical between the two parents, but differences were found in BnaA05g16700D and BnaA05g16720D. Two singlenucleotide transition mutations, leading to two amino-

Table 4 Analysis of variance of maker genotypes on plant heights in the $\mathrm{BC}_{5} \mathrm{~F}_{3}(1)$ and $\mathrm{BC}_{5} \mathrm{~F}_{3}$ (2) populations derived from NJAU5737 and the recurrent parent ZS11

\begin{tabular}{llllll}
\hline Population & Source & DF & SS & MS & $F$ \\
\hline $\mathrm{BC}_{5} \mathrm{~F}_{3}(1)$ & Marker genotype & 2 & $265,238.81$ & $132,619.41$ & $1152.85^{* *}$ \\
& Error & 865 & $99,506.44$ & 115.04 & 4.63 \\
& Total & 867 & $364,745.25$ & & \\
$\mathrm{BC}_{5} \mathrm{~F}_{3}(2)$ & Marker genotype & 2 & $231,933.09$ & $115,966.54$ & $939.77^{* *}$ \\
& Error & 790 & $97,485.43$ & 123.40 & 4.63 \\
& Total & 792 & $329,418.51$ & & \\
& & & & \\
\end{tabular}

** indicates significant differences at 0.01 probability level 
Table 5 Average plant heights of three marker-genotypes in the $\mathrm{BC}_{5} \mathrm{~F}_{3}(1)$ and $\mathrm{BC}_{5} \mathrm{~F}_{3}$ (2) populations derived from NJAU5737 and the recurrent parent $\mathrm{ZS} 11$

\begin{tabular}{llll}
\hline Population & Genotype & Sample size & Mean $\pm \mathrm{SD}(\mathrm{cm})$ \\
\hline $\mathrm{BC}_{5} \mathrm{~F}_{3}(1)$ & Normal flat leaf & 227 & $170.60 \pm 11.95 \mathrm{~A}$ \\
& Heterozygous up-curled leaf & 430 & $146.46 \pm 11.75 \mathrm{~B}$ \\
& Homozygous up-curled leaf & 211 & $121.36 \pm 6.03 \mathrm{C}$ \\
$\mathrm{BC}_{5} \mathrm{~F}_{3}(2)$ & Normal flat leaf & 205 & $169.02 \pm 12.45 \mathrm{~A}$ \\
& Heterozygous up-curled leaf & 405 & $147.89 \pm 11.85 \mathrm{~B}$ \\
& Homozygous up-curled leaf & 183 & $120.12 \pm 6.94 \mathrm{C}$ \\
\hline
\end{tabular}

Values in a column followed by different letters indicate significant differences by $L S D(P=0.01)$

acid substitutions at positions 30 and 63 (Fig. 4), were present in BnaA05g16700D (named BnaA05.IAA2) of NJAU5737. The substitution at amino-acid position 63 was located in the Degron motif (GWPPV) of domain II, which is strongly conserved in most plant IAA family members. BnaA05g16700D is thus the gene most likely corresponding to the BnUC2 locus. We then developed a pair of site specific CAPS marker (Additional file 4: Table S3) based on the variant site on the Degron motif (GWPPV) of BnaA05.IAA2, which completely cosegregated with the phenotypes in the $\mathrm{BC}_{5} \mathrm{~F}_{3}$ population (Additional file 5: Fig. S2). These results demonstrated that BnaA05g16700D is thus the gene most likely corresponding to the BnUC2 locus.

\section{Agronomic traits}

To evaluate the effect of the BnUC2 locus on plant agronomic traits, 20 plants with up-curled leaves and 20 with flat leaves were randomly sampled from the $\mathrm{BC}_{6}$ population derived from NJAU5737 and recurrent parent ZS11. Plant height, branching height, main inflorescence length, and silique length were significantly smaller in up-curled-leaf plants than in flat-leaf plants, with no alterations observed in other analyzed traits (Table 7). These results indicate that the $B n U C 2$ locus significantly reduces plant height, branching height, and main inflorescence length but has no significant influence on yield.

\section{Discussion}

A plant type with upright leaves and a short stature is undoubtedly beneficial for the improvement of crop yield and lodging resistance [2]. In B. napus, the mechanisms underlying plant height are complex, and many plant height loci/QTLs have been reported [17, 51, 58, 59, 61, 70-74]. No technical breakthroughs have yet been achieved in the breeding of dwarf stature canola variety, however, and further mining and utilization of new dwarf or semi-dwarf germplasm resources is thus required. In the present study, we characterized a novel germplasm resource with up-curled leaves and a semidwarf stature. We identified a locus, BnUC2, in this germplasm resource that exhibited dominance in the populations but had mainly additive effects on plant height and explained 72.72 and $70.41 \%$ of phenotypic variation in plant height in the two $\mathrm{BC}_{5} \mathrm{~F}_{3}$ family populations. These results suggest that the up-curled leaf trait of the $B n u c 2$ can serve as an indicator trait for semidwarf variety breeding. Meanwhile, it can be useful for increasing planting density, with the aim of elevating $B$. napus yield. In addition, heterozygous $B n U C 2$ locus does not have any significant effect on yield per plant. Thus, the newly characterized germplasm resource harboring the BnUC2 locus may probably be an aid in Brassica variety breeding.

Our primary mapping of $B n U C 2$ positioned this locus within a 3.84-Mb interval, which corresponds to a recombination rate of $0.8 \%$ based on the linkage map. This value is far larger than the B. napus genome-level average of $400 \mathrm{~kb} / \mathrm{cM}$ [75], this is most likely because the BnUC2 locus is located near the chromosome A05 centromere that affects chromosomal recombination. This may also be caused by the limited number of plants used for primary mapping. To fine map the BnUC2 locus, we expanded the mapping population and 1661 $\mathrm{BC}_{5} \mathrm{~F}_{3}$ plants were obtained, leading to a fine-mapping interval of $83.19-\mathrm{kb}$ in length, with a corresponding recombination rate of $0.06 \%$.

On the basis of our mapping, gene sequencing, and bioinformatics analysis results, BnaA05.IAA2 is the gene most likely responsible for leaf up-curling and plant semi-dwarfing. This gene encodes an AUX/IAA2 protein that acts as a repressor of auxin-regulated transcriptional activation. Two single amino-acid changes were identified in the AUX/IAA2 protein. The substitution at amino-acid position 63, located in the domain-II Degron motif (GWPPV) conserved in most plants, is key to the

Table 6 Function annotation of genes in the mapping interval

\begin{tabular}{llll}
\hline Gene in B. napus & Chromosome position & Homologue in A. thaliana & Gene annotations \\
\hline BnaA05g16680D & $11341560-11342921$ & AT3G23050.1 & Aux/IAA7 protein \\
BnaA05g16690D & $11375956-11376874$ & & unknown protein \\
BnaA05g16700D & $11384467-11385470$ & AT3G23030.1 & Aux/IAA2 protein \\
BnaA05g16710D & $11398936-11401491$ & AT3G23020.1 & Tetratricopeptide repeat (TPR)-like superfamily protein \\
BnaA05g16720D & $11401616-11403042$ & AT3G23000.1 & CBL-interacting protein kinase 7 \\
\hline
\end{tabular}




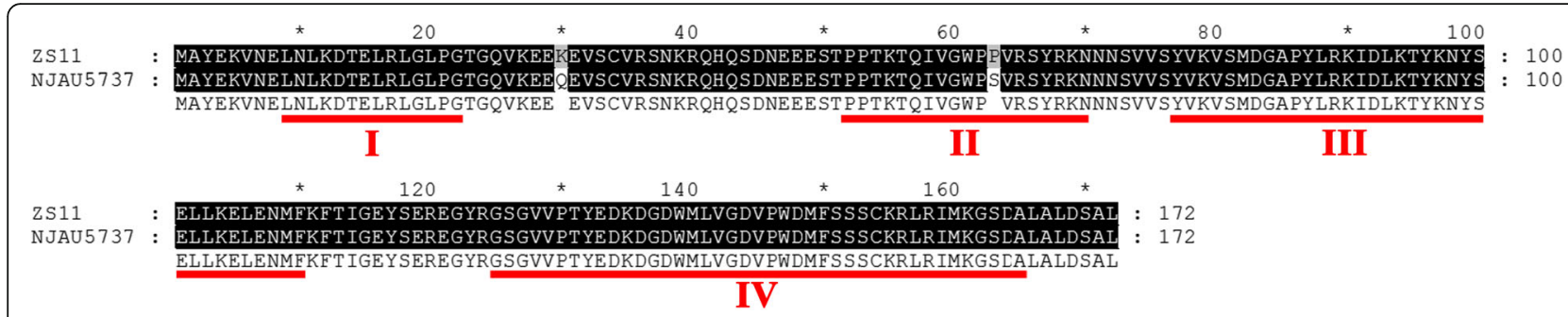

Fig. 4 Amino acid sequence alignment of BnaA05916700D (BnaA05.IAA2) in ZS11 and NJAU5737. Four conserved domain of BnaA05g16700D were designated as I, II, III and IV, indicated by red underline

phenotypic mutation [41]. Auxin, one of the most important hormones in plants [76, 77], is involved in the regulation of multiple traits, including leaf type and plant height $[34,47$, $65,78]$. Mutations of genes related to auxin synthesis and signal transduction may lead to leaf curling and dwarf/semidwarf phenotypes. BnaA05.IAA2 is thus the reliable candidate gene and has a pleiotropic effect on leaf type and plant height. Another candidate gene, BnaA05g16720D, with coding sequence mutations related to stress response [68, 69], could not be excluded completely.

\section{Conclusions}

A novel pure accession with up-curled leaves and a semi-dwarf stature found in oilseed rape breeding was used for investigation of the mutated leaf and plant type trait. Results showed that the up-curled leaf trait was controlled by a dominant locus (BnUC2) fine-mapped onto an 83.19-kb interval on chromosome A05 using SNP and SSR markers. Our results have also been found that $B n U C 2$ is a major plant height QTL responsible for the observed semi-dwarf stature. Comparative sequencing shows that BnaA05g16700D (BnaA05.IAA2) and BnaA05g16720D in the fine mapping interval which contains five genes, are mutated in NJAU5737. A substitution (P63S) of BnaA05.IAA2 in NJAU5737 found in the conserved Degron motif GWPPV completely cosegregated with the phenotypes as demonstrated by the specific CAPS marker experiments. This mutation is of functionality, may probably result in the phenotype of up-curled leaves and a semi-dwarf stature. Our findings may provide an effective foundation for the semi-dwarf variety breeding of $B$. napus and exploration of the leaf up-curling and dwarfing mechanism.

\section{Methods}

Plant materials and analysis of inheritance of the upcurled leaf trait

The Bnuc2 mutant exhibiting leaf up-curling and a semi-dwarf stature was derived from a pure canola line, NJAU5737. NJAU5737 was crossed with canola variety ZS11 to produce the $F_{1}$ generation. The $F_{1}$ individuals were then backcrossed with ZS11 to produce progeny populations. The self and backcross populations were examined to determine the segregation ratio of plants with up-curled vs. flat leaves. Chi-square tests were performed to test the genetic regulation of the up-curled leaf trait. $\mathrm{BC}_{5}, \mathrm{BC}_{6}$, and $\mathrm{BC}_{5} \mathrm{~F}_{2}$ family populations derived from NJAU5737 and ZS11 were used for preliminary mapping of the up-curled leaf trait locus $B n U C 2$,

Table 7 Agronomic traits of flat leaf and up-curled leaf plants in the BC 6 derived from NJAU5737 and the recurrent parent ZS11

\begin{tabular}{|c|c|c|}
\hline Trait & Flat leaf plants & Up-curled leaf plants \\
\hline Plant height $(\mathrm{cm})$ & $175.64 \pm 13.67$ & $149.64 \pm 13.99^{a}$ \\
\hline Branching height $(\mathrm{cm})$ & $61.75 \pm 9.57$ & $54.53 \pm 9.55^{b}$ \\
\hline Main inflorescence length $(\mathrm{cm})$ & $71.29 \pm 8.33$ & $54.64 \pm 8.82^{a}$ \\
\hline Number of first effective branch & $6.90 \pm 1.45$ & $6.20 \pm 1.14$ \\
\hline Stem diameter (mm) & $20.38 \pm 3.33$ & $18.22 \pm 3.20$ \\
\hline Number of siliques on the main inflorescence & $77.5 \pm 11.1$ & $70.3 \pm 8.6$ \\
\hline Total siliques per plant & $395.4 \pm 89.3$ & $351.6 \pm 95.1$ \\
\hline Silique length (cm) & $10.11 \pm 0.97$ & $9.43 \pm 1.09^{b}$ \\
\hline Seeds per siliques & $25.38 \pm 3.74$ & $26.46 \pm 3.09$ \\
\hline 1000-seed weight (g) & $4.75 \pm 0.14$ & $4.54 \pm 0.11$ \\
\hline Yield per plant (g) & $24.61 \pm 11.68$ & $21.08 \pm 9.35$ \\
\hline
\end{tabular}

${ }^{\mathrm{a}}$ and $^{\mathrm{b}}$ indicate significant differences at 0.01 and 0.05 probability level by $t$-test, respectively. Data are shown as mean $\pm S D, n=20$ 
and the $\mathrm{BC}_{5} \mathrm{~F}_{3}$ family population was used for fine mapping the BnUC2 locus.

All materials were grown in fields at the Jiangpu Experimental Station of Nanjing Agricultural University (Jiangsu Province, China). Plants were sown uniformly in $2.5-\mathrm{m}$ long rows, with $0.4 \mathrm{~m}$ between rows and 15 individuals per row.

\section{SNP analysis}

Eight $\mathrm{BC}_{5}$ plants with up-curled leaves and the two parents (ZS11 and NJAU5737) were selected for SNP genotyping using a Brassica $60 \mathrm{~K}$ SNP bead chip array (Illumina, US). The genotyping was performed to detect chromosome segments differing between the backcross progeny population and ZS11, thereby preliminarily identifying the chromosome on which the $B n U C 2$ locus was located. The SNP marker was named using "M" plus an index number specified by Genome Studio v2011.1 (Illumina, US). The SNP analysis was identical to that of a previous study [61].

SNPs on 19 chromosomes were compared between the eight up-curled-leaf plants and the recurrent parent ZS11 to determine differential chromosome segments. The $\mathrm{BC}_{5}$ plant having the fewest genome-level differences with ZS11, BnUC2-5, possessed three differential segments located on chromosomes A05, C02, and C07.

\section{Genetic mapping of the BnUC2 locus}

BnUC2-5 was selfed and backcrossed with ZS11, and $286 \mathrm{BC}_{5} \mathrm{~F}_{2}$ and $246 \mathrm{BC}_{6}$ individuals were obtained for mapping the $B n U C 2$ locus, respectively.

SSR-marker primers were designed in Primer Premier 5.0 [79] using the genomic sequences of the three differential fragments downloaded from the B. napus Genome Browser. SSR markers that were polymorphic between BnUC2-5, ZS11, and NJAU5737 were used to detect polymorphisms in all plants in $\mathrm{BC}_{6}$ and $\mathrm{BC}_{5} \mathrm{~F}_{2}$ family populations. Recombination frequencies between SSR markers and the BnUC2 locus were calculated using JoinMap 4.1 software to determine the chromosome harboring the $B n U C 2$ locus.

For fine mapping of the $B n U C 2$ locus, we used 1661 $\mathrm{BC}_{5} \mathrm{~F}_{3}$ plants obtained from non-recombinant $\mathrm{BC}_{5} \mathrm{~F}_{2}$ plants. On the basis of preliminary mapping results, polymorphic SSR markers were gradually developed, and a genetic map was constructed in JoinMap 4.1 to narrow the interval containing the $B n U C 2$ locus.

Polymerase chain reaction (PCR) amplifications of molecular markers were performed as described previously [54]. Total DNA extraction and linkage map construction were carried out according to previous reports [61].

\section{Identification of genes in the mapping interval and comparative sequencing}

To identify genes in the mapping interval, the genomic sequence of the mapping interval carrying the $B n U C 2$ locus was downloaded from the B. napus Genome Browser. Genes detected in the mapping interval were annotated and then cloned. Gene-amplification primers based on the genomic sequence were designed using Primer Premier 5.0 (Additional file 4: Table S3). Full-length sequences of genes in the mapping interval were amplified using genomic DNA and cDNA from parents NJAU5737 and ZS11.

PCR amplifications were performed in $50-\mu \mathrm{L}$ reaction volumes using PrimeSTAR Max DNA polymerase (Takara, Tokyo, Japan). The PCR conditions were as follows: $94{ }^{\circ} \mathrm{C}$ for $2 \mathrm{~min}$, followed by 35 cycles of $98^{\circ} \mathrm{C}$ for $10 \mathrm{~s}$, annealing for $5 \mathrm{~s}$ at the annealing temperature of each gene-amplification primer, and $72^{\circ} \mathrm{C}$ for 30 s, with a final extension of $72{ }^{\circ} \mathrm{C}$ for $5 \mathrm{~min}$.

The PCR products were purified using a AxyPrep DNA Gel Extraction kit and sequenced by GenScript Biotech (Nanjing, China). The resulting sequences were aligned using Clustal X and GeneDoc software.

\section{Development of site specific CAPS marker}

Based on the comparative sequencing, nucleotides at positions 184-187 were CCTC in parent ZS11, and has been mutated to CCTT in parent NJAU5737. To detect this single-nucleotide transition mutation, specific CAPS primers (Additional file 4: Table S3) were designed to PCR amplifications. The PCR products were $186 \mathrm{bp}$ long and then were digested using MnlI (Catalog R0163S, New England Biolabs, recognition site: CCTC). The PCR products containing the CCTC recognition site were cut into two segments, $127 \mathrm{bp}$ and $59 \mathrm{bp}$ in length, respectively. Then the polymorphic bands were separated by polyacrylamide gel electrophoresis.

\section{Agronomic traits}

We randomly selected 20 up-curled-leaf and 20 flat-leaf plants from the $\mathrm{BC}_{6}$ population to investigate traits for evaluation of the effect of heterozygous $B n U C 2$ locus on plant agronomic efficiency. The agronomic trait data included plant height, branching height, main inflorescence length, number of first effective branch, stem diameter, number of siliques on the main inflorescence, total siliques per plant, silique length, seeds per siliques, 1000 -seed weight, and yield per plant. The mean values of all agronomic traits between up-curled-leaf and flatleaf plants were compared by $t$-tests.

Heights of all plants in two $\mathrm{BC}_{5} \mathrm{~F}_{3}$ family populations were determined, and an ANOVA was applied to estimate the genetic variance, error variance, and phenotypic variation of this trait. 


\section{Determination of chlorophyll content and photosynthetic efficiency}

We randomly selected 15 homozygous up-curled-leaf and 15 flat-leaf plants from the $\mathrm{BC}_{5} \mathrm{~F}_{3}$ population at the seedling stage for determination of chlorophyll content. Chlorophyll (Chl) was extracted from 0.2-g fresh leaves with $50 \mathrm{ml}$ of $80 \%$ acetone, and Chl contents were determined using an Alpha-1500 spectrophotometer (LASP

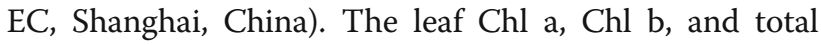
$\mathrm{Chl}$ contents were measured as described previously [80].

Six homozygous up-curled-leaf and six flat-leaf plants were selected randomly from the $\mathrm{BC}_{5} \mathrm{~F}_{3}$ population at the seedling stage for determination of photosynthetic efficiency. The photosynthetic characteristics were determined using a Li-Cor 6400 portable photosynthesis system (Li-Cor Inc., Lincoln, NE, USA) at $23^{\circ} \mathrm{C}$ as described previously [54]. All data were collected between 09:00 am and 11:00 am.

\section{Supplementary information}

Supplementary information accompanies this paper at https://doi.org/10. 1186/s12864-020-06947-7.

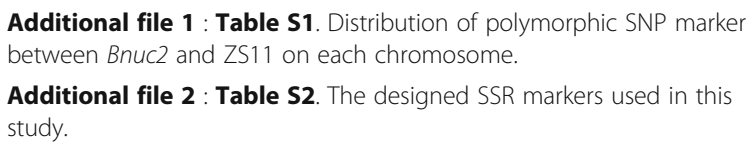

Additional file 4 : Table S3. The designed primers of comparative sequencing and CAPS marker used in this study.

Additional file $\mathbf{5}$ : Figure S2. Part of marker experimental results for CAPS marker.

Additional file $\mathbf{6}$ : Figure S3. Full-length, original blots image of Fig. 3.

\section{Abbreviations}

B. napus: Brassica napus; BnUC2: Up-curled leaf locus in B. napus genome; Bnuc2: Up-curled leaf mutant; Chl: Chlorophyll; PCR: Polymerase chain reaction; TIR1/AFB: Transport inhibitor resistant1/auxin signaling F-box; ARF: Auxin response factor; SNP: Single nucleotide polymorphism; SSR: Simple sequence repeat; TAIR: The Arabidopsis Information Resource; ZS11: Zhongshuang 11; ANOVA: Analysis of variance; QTL: Quantitative Trait Locus; HD-ZIP III: Class III HOMEODOMAIN LEUCINE-ZIPPER; WOX: WUSCHEL RELATED HOMEOBOX; TCP: TB1-CYC-PCFs; AuX/IAA: AUXIN/INDOLE-3-ACETIC $A C I D$

\section{Acknowledgments}

Not applicable.

\section{Authors' contributions}

RG conceived and designed the study. $\mathrm{CH}$ performed most of the experiments and wrote the manuscript. RG advised on the experiments and modified the manuscript. MY, DS, YW, and SW took part in the DNA extraction and marker experiments. JH and ZM carried out sequence analysis. All authors read and approved the final manuscript.

\section{Funding}

This research was supported financially by the National Key Research and Development Plan (2018YFD0100600), the National Natural Science Foundation of China (31270386), partly by the open funds of the State Key Laboratory of Crop Genetics and Germplasm Enhancement (ZW201802), and the Cyrus Tang Seed Innovation Center, Nanjing Agricultural University. The funders provided the financial support to the research, but had no role in the design of the study, analysis, interpretations of data and in writing the manuscript.

\section{Availability of data and materials}

The datasets generated and/or analysed during the current study are available in the Figshare repository (https://doi.org/10.6084/m9.figshare. 12689615).

\section{Ethics approval and consent to participate}

Not applicable.

\section{Consent for publication}

Not applicable.

\section{Competing interests}

The authors declare that they have no competing interests.

\section{Author details}

${ }^{1}$ National Key Laboratory of Crop Genetics and Germplasm Enhancement, Jiangsu Collaborative Innovation Center for Modern Crop Production, Nanjing Agricultural University, Nanjing 210095, China. ${ }^{2}$ Tibet Agriculture and Animal Husbandry College, Linzhi 860000, Tibet Autonomous Region, China.

Received: 2 November 2019 Accepted: 24 July 2020

Published online: 31 July 2020

\section{References}

1. Lang Y, Zhang Z, Gu X, Yang J, Zhu Q. Physiological and ecological effects of crimpy leaf character in rice (Oryza sativa L.) I. leaf orientation, canopy structure and light distribution. Acta Agron Sin. 2004;30(8):806-10.

2. Hedden P. The genes of the green revolution. Trends Genet. 2003;19(1):5-9.

3. Fei D, Guan C, Jiao Y. Molecular mechanisms of leaf morphogenesis. Mol Plant. 2018;11(9):1117-34.

4. Conklin PA, Josh S, Shujie L, SM J. On the mechanisms of development in monocot and eudicot leaves. New Phytol. 2019;221(2):706-24.

5. Hudson A, Waites R. Early events in leaf development. Semin Cell Dev Biol. 1998;9(2):207-11.

6. Zhang $\mathrm{GH}$, Xu Q, Zhu XD, Qian Q, Xue HW. SHALLOT-LIKE1 is a KANADI transcription factor that modulates rice leaf rolling by regulating leaf abaxial cell development. Plant Cell. 2009:21(3):719-35.

7. Zumajo-Cardona C, Vasco A, Ambrose BA. The evolution of the KANADI gene family and leaf development in Lycophytes and ferns. Plants. 2019; 8(9):313.

8. Merelo P, Paredes EB, Heisler MG, Wenkel S. The shady side of leaf development: the role of the REVOLUTA/KANADI1 module in leaf patterning and auxin-mediated growth promotion. Curr Opin Plant Biol. 2017:35:111-6.

9. Huang T, Harrar Y, Lin C, Reinhart B, Newell NR, Talaverarauh F, Hokin SA, Barton MK, Kerstetter RA. Arabidopsis KANADI1 acts as a transcriptional repressor by interacting with a specific cis-element and regulates auxin biosynthesis, transport, and signaling in opposition to HD-ZIPIII factors. Plant Cell. 2014;26(1):246.

10. Ilegems M, Douet V, Meylan-Bettex M, Uyttewaal M, Brand L, Bowman JL, Stieger PA. Interplay of auxin, KANADI and class III HD-ZIP transcription factors in vascular tissue formation. Development. 2010;137(6):975-84.

11. Rong F, Chen F, Huang L, Zhang J, Zhang C, Hou D, Cheng Z, Weng Y, Chen P, Li Y. A mutation in class III homeodomain-leucine zipper (HD-ZIP III) transcription factor results in curly leaf (cul) in cucumber (Cucumis sativus L. ). Theor Appl Genet. 2019;132(1):113-23.

12. Li YY, Shen A, Xiong W, Sun QL, Luo Q, Song T, Li ZL, Luan WJ. Overexpression of OsHox32 results in pleiotropic effects on plant type architecture and leaf development in Rice. Rice. 2016:9(1):46.

13. Merelo P, Ram H, Caggiano MP, Ohno C, Heisler MG. Regulation of MIR165/ 166 by class II and class III homeodomain leucine zipper proteins establishes leaf polarity. Proc Natl Acad Sci U S A. 2016;113(42):11973-8.

14. Cho SH, Yoo SC, Zhang H, Pandeya D, Koh HJ, Hwang JY, Kim GT, Paek NC. The rice narrow leaf2 and narrow leaf3 loci encode WUSCHEL-related homeobox 3A (OsWOX3A) and function in leaf, spikelet, tiller and lateral root development. New Phytol. 2013;198(4):1071-84. 
15. Koyama T, Sato F, Ohme-Takagi M. Roles of miR319 and TCP transcription factors in leaf development. Plant Physiol. 2017;175(2):874-85.

16. Mai $Y X$, Wang L, Yang HQ. A gain-of-function mutation in IAA7/AXR2 confers late flowering under short-day light in Arabidopsis. J Integr Plant Biol. 2011;53(6):480-92.

17. Zhao B, Wang B, Li Z, Guo T, Zhao J, Guan Z, Liu K. Identification and characterization of a new dwarf locus DS-4 encoding an aux/IAA7 protein in Brassica napus. Theor Appl Genet. 2019;132(5):1435-49.

18. Liu S, Hu Q, Sha L, Li Q, Yang X, Wang X, Wang S. Expression of wild-type PtrIAA14.1, a poplar aux/IAA gene causes morphological changes in Arabidopsis. Front. Plant Sci. 2015;6:388.

19. Hou Y, Li H, Zhai L, Xie X, Li X, Bian S. Identification and functional characterization of the Aux/IAA gene VCIAA27 in blueberry. Plant Signal Behav. 2020;15(1):1700327.

20. Pekker I, Alvarez JP, Eshed Y. Auxin response factors mediate Arabidopsis organ asymmetry via modulation of KANADI activity. Plant Cell. 2005;17(11): 2899-910.

21. Pérez-Pérez JM, Ponce MR, Micol JL. The UCU1 Arabidopsis gene encodes a SHAGGY/GSK3-like kinase required for cell expansion along the proximodistal axis. Dev Biol. 2002;242(2):161-73.

22. Prigge M, Otsuga D, Alonso JM, Ecker JR, Drews GN, Clark SE. Class III homeodomain-leucine zipper gene family members have overlapping, antagonistic, and distinct roles in Arabidopsis development. Plant Cell. 2005;17(1):61-76.

23. Juarez MT, Kui JS, Thomas J, Heller BA, Timmermans MC. microRNAmediated repression of rolled leaf1 specifies maize leaf polarity. Nature. 2004;428(6978):84

24. Tatematsu K, Toyokura K, Miyashima S, Nakajima K, Okada K. A molecular mechanism that confines the activity pattern of miR165 in Arabidopsis leaf primordia. Plant J. 2015;82(4):596-608.

25. Mallory AC, Vaucheret $H$. Functions of microRNAs and related small RNAs in plants. Nat Genet. 2006;38(Suppl):S31-6.

26. Liu PP, Montgomery TA, Fahlgren N, Kasschau KD, Nonogaki H, Carrington JC. Repression of AUXIN RESPONSE FACTOR10 by microRNA160 is critical for seed germination and post-germination stages. Plant J. 2007;52(1):133-46.

27. Nikovics K, Blein T, Peaucelle A, Ishida T, Morin H, Aida M, Laufs P. The balance between the MIR164A and CUC2 genes controls leaf margin serration in Arabidopsis. Plant Cell. 2006;18(11):2929-45.

28. Wu Z, Tang D, Liu K, Miao C, Zhuo X, Li Y, Tan X, Sun M, Luo Q, Cheng Z. Characterization of a new semi-dominant dwarf allele of SLR1 and its potential application in hybrid rice breeding. J Exp Bot. 2018;69(20):4703-13.

29. Cassani E, Bertolini E, Cerino Badone F, Landoni M, Gavina D, Sirizzotti A, Pilu R. Characterization of the first dominant dwarf maize mutant carrying a single amino acid insertion in the VHYNP domain of the dwarf8 gene. Mol Breed. 2009;24(4):375-85

30. Makarevitch I, Thompson A, Muehlbauer GJ, Springer NM. Brd1 gene in maize encodes a brassinosteroid C-6 oxidase. PLoS One. 2012;7(1):e30798.

31. Feng Y, Yin Y, Fei S. Down-regulation of BdBRI1, a putative brassinosteroid receptor gene produces a dwarf phenotype with enhanced drought tolerance in Brachypodium distachyon. Plant Sci. 2015;234:163-73.

32. Braun E-M, Tsvetkova NV, Rotter B. Musmann DSg, Hackauf B. gene expression profiling and fine mapping identifies a gibberellin 2-oxidase gene co-segregating with the dominant dwarfing gene Ddw1 in Rye (Secale cereale L.). Front Plant Sci. 2019;10:857.

33. Hirano K, Kawamura M, Araki-Nakamura S, Fujimoto H, Ohmae-Shinohara K, Yamaguchi M, Fujii A, Sasaki H, Kasuga S, Sazuka T. Sorghum DW1 positively regulates brassinosteroid signaling by inhibiting the nuclear localization of BRASSINOSTEROID INSENSITIVE 2. Sci Rep. 2017;7(1):126.

34. Cheng Y. Auxin biosynthesis by the YUCCA flavin monooxygenases controls the formation of floral organs and vascular tissues in Arabidopsis. Genes Dev. 2006;20(13):1790-9.

35. Cao X, Yang H, Shang C, Ma S, Liu L, Cheng J. The roles of auxin biosynthesis YUCCA gene family in plants. Int J Mol Sci. 2019;20(24):6343.

36. Blakeslee JJ, Peer WA, Murphy AS. Auxin transport. Curr Opin Plant Biol. 2005;8(5):494-500.

37. Noh B, Murphy AS, Spalding EP. Multidrug resistance-like genes of Arabidopsis required for auxin transport and auxin-mediated development. Plant Cell. 2001;13(11):2441-54.

38. Dharmasiri N, Estelle M. Auxin signaling and regulated protein degradation. Trends Plant Sci. 2004;9(6):302-8.

39. Luo J, Zhou JJ, Zhang JZ. AuX/IAA gene family in plants: molecular structure, regulation, and function. Int J Mol Sci. 2018;19(1):259.
40. Hirotaka K, Ryuichi N, Dolf W, Takayuki K. Evolution of nuclear auxin signaling: lessons from genetic studies with basal land plants. J Exp Bot. 2018;69(2):291-301.

41. Jain M, Khurana JP. Transcript profiling reveals diverse roles of auxinresponsive genes during reproductive development and abiotic stress in rice. FEBS J. 2009;276(11):3148-62.

42. Han S, Ildoo H. Integration of multiple signaling pathways shapes the auxin response. J Exp Bot. 2018;69(2):189-200.

43. Gray WM, Kepinski S, Rouse D, Leyser O, Estelle M. Auxin regulates SCF TIR1dependent degradation of AUX/IAA proteins. Nature. 2001;414(6861):271.

44. Hagen G, Guilfoyle T. Auxin-responsive gene expression: genes, promoters and regulatory factors. Plant Mol Biol. 2002;49(3-4):373-85.

45. Leyser O. Auxin Signaling. Plant Physiol. 2018;176(1):465-79.

46. Hagen G. Auxin signal transduction. Essays Biochem. 2015;58:1-12.

47. Overvoorde PJ, Okushima Y, Alonso JM, Chan A, Chang C, Ecker JR, Hughes B, Liu A, Onodera C, Quach $\mathrm{H}$, et al. Functional genomic analysis of the AUXIN/INDOLE-3-ACETIC ACID gene family members in Arabidopsis thaliana. Plant Cell. 2005;17(12):3282-300.

48. Uehara T, Okushima Y, Mimura T, Tasaka M, Fukaki H. Domain II mutations in CRANE/IAA18 suppress lateral root formation and affect shoot development in Arabidopsis thaliana. Plant Cell Physiol. 2008;49(7):1025-38.

49. Jiang M, Hu H, Kai J, Traw MB, Yang S, Zhang X. Different knockout genotypes of OSIAA23 in rice using CRISPR/Cas9 generating different phenotypes. Plant Mol Biol. 2019;100(4-5):467-79.

50. Tian Q, Uhlir NJ, Reed JW. Arabidopsis SHY2/IAA3 inhibits auxin-regulated gene expression. Plant Cell. 2002;14(2):301-19.

51. Li H, Li J, Song J, Zhao B, Guo C, Wang B, Zhang Q, Wang J, King GJ, Liu K. An auxin signaling gene BnaA3.IAA7 contributes to improved plant architecture and yield heterosis in rapeseed. New Phytol. 2019;222(2):837-51.

52. Cheng H, Jin F, Zaman QU, Ding B, Hu Q. Identification of Bna.IAA7.C05 as allelic gene for dwarf mutant generated from tissue culture in oilseed rape. BMC Plant Biol. 2019;19(1):500.

53. Wang Y, Chen W, Chu P, Wan S, Yang M, Wang M, Guan R. Mapping a major QTL responsible for dwarf architecture in Brassica napus using a single-nucleotide polymorphism marker approach. BMC Plant Biol. 2016; 16(1):178.

54. Yang M, Huang C, Wang M, Fan H, Wan S, Wang Y, He J, Guan R. Fine mapping of an up-curling leaf locus (BnUC1) in Brassica napus. BMC Plant Biol. 2019;19(1):324.

55. Foisset N, Delourme R, Barret P, Hubert N, Landry B, Renard M. Molecularmapping analysis in Brassica napus using isozyme, RAPD and RFLP markers on a doubled-haploid progeny. Theor Appl Genet. 1996;93(7):1017-25.

56. Wang M, Zhao Y, Chen F, Yin X. Inheritance and potentials of a mutated dwarfing gene ndf1 in Brassica napus. Plant Breed. 2004;123(5):449-53.

57. Mei D-S, Wang H-Z, Li Y-C, Hu Q, Li Y-D, Xu Y-S. The discovery and genetic analysis of dwarf mutation 99CDAM in Brassica napus L. Hereditas. 2006; 28(7):851-7.

58. Liu C, Wang J, Huang T, Wang F, Yuan F, Cheng X, Zhang Y, Shi S, Wu J, Liu K. A missense mutation in the VHYNP motif of a DELLA protein causes a semi-dwarf mutant phenotype in Brassica napus. Theor Appl Genet. 2010; 121(2):249-58.

59. Zhao B, Li H, Li J, Wang B, Dai C, Wang J, Liu K. Brassica napus DS-3, encoding a DELLA protein, negatively regulates stem elongation through gibberellin signaling pathway. Theor Appl Genet. 2017;130(4):727-41.

60. Zeng X, Zhu L, Chen Y, Qi L, Pu Y, Wen J, Yi B, Shen J, Ma C, Tu J, et al. Identification, fine mapping and characterisation of a dwarf mutant (bnaC. dwf) in Brassica napus. Theor Appl Genet. 2010;122(2):421-8.

61. Wang Y, He J, Yang L, Wang Y, Chen W, Wan S, Chu P, Guan R. Fine mapping of a major locus controlling plant height using a high-density single-nucleotide polymorphism map in Brassica napus. Theor Appl Genet. 2016;129(8):1479-91.

62. Law CN, Snape JW, Worland AJ. The genetical relationship between height and yield in wheat. Heredity. 1978;40(1):133-51.

63. Wang JK, Gai JY. Identification of major gene and polygene mixed inheritance model and estimation of genetic parameters of a quantitative trait from F2 progeny. J Genet Genom. 1997;24(5):432-40.

64. Lavy M, Estelle M. Mechanisms of auxin signaling. Development. 2016; 143(18):3226-9.

65. Yang $X$, Lee $S$, So JH, Dharmasiri S, Dharmasiri N, Ge L, Jensen C, Hangarter $\mathrm{R}$, Hobbie L, Estelle M. The IAA1 protein is encoded by AXR5 and is a substrate of SCFTIR1. Plant J. 2004;40(5):772-82. 
66. Tian $\mathrm{Q}$, Reed JW. Control of auxin-regulated root development by the Arabidopsis thaliana SHY2/IAA3 gene. Development. 1999;126(4):711-21.

67. Timpte C, Wilson AK, Estelle M. The axr2-1 mutation of Arabidopsis thaliana is a gain-of-function mutation that disrupts an early step in auxin response. Genetics. 1994;138(4):1239-49.

68. Kobayashi M, Horiuchi H, Fujita K, Takuhara Y, Suzuki S. Characterization of grape C-repeat-binding factor 2 and B-box-type zinc finger protein in transgenic Arabidopsis plants under stress conditions. Mol Biol Rep. 2012; 39(8):7933-9.

69. Huang C, Ding S, Zhang H, Du H, An L. CIPK7 is involved in cold response by interacting with CBL1 in Arabidopsis thaliana. Plant Sci. 2011;181(1):5764.

70. Basunanda P, Radoev M, Ecke W, Friedt W, Becker HC, Snowdon RJ. Comparative mapping of quantitative trait loci involved in heterosis for seedling and yield traits in oilseed rape (Brassica napus L.). Theor Appl Genet. 2010;120(2):271-81.

71. Ding G, Zhao Z, Liao Y, Hu Y, Shi L, Long Y, Xu F. Quantitative trait loci for seed yield and yield-related traits, and their responses to reduced phosphorus supply in Brassica napus. Ann Bot. 2012;109(4):747-59.

72. Li F, Chen B, Xu K, Gao G, Yan G, Qiao J, Li J, Li H, Li L, Xiao X, et al. A genome-wide association study of plant height and primary branch number in rapeseed (Brassica napus). Plant Sci. 2016;242:169-77.

73. Luo X, Ma C, Yue Y, Hu K, Li Y, Duan Z, Wu M, Tu J, Shen J, Yi B, et al. Unravelling the complex trait of harvest index in rapeseed (Brassica napus $\mathrm{L}$. ) with association mapping. BMC Genomics. 2015;16:379.

74. Wang X, Wang H, Long Y, Liu L, Zhao Y, Tian J, Zhao W, Li B, Chen L, Chao $\mathrm{H}$, et al. Dynamic and comparative QTL analysis for plant height in different developmental stages of Brassica napus L. Theor Appl Genet. 2015;128(6): 1175-92.

75. Schmidt R, Bancroft I. Genetics and genomics of the Brassicaceae. 1rd ed. New York: Springer; 2011.

76. Teale WD, Paponov IA, Palme K. Auxin in action: signalling, transport and the control of plant growth and development. Nat Rev Mol Cell Biol. 2006 7(11):847-59.

77. Mockaitis K, Estelle M. Auxin receptors and plant development: a new signaling paradigm. Annu Rev Cell Dev Biol. 2008;24:55-80.

78. Reed JW. Roles and activities of aux/IAA proteins in Arabidopsis. Trends Plant Sci. 2001;6(9):420-5.

79. Singh VK, Mangalam A, Dwivedi S, Naik S. Primer premier: program for design of degenerate primers from a protein sequence. Biotechniques. 1998;24(2):318-9.

80. Arnon DI. Copper enzymes in isolated chloroplasts. Polyphenoloxidase in Beta vulgaris. Plant Physiol. 1949;24(1):1.

\section{Publisher's Note}

Springer Nature remains neutral with regard to jurisdictional claims in published maps and institutional affiliations.

Ready to submit your research? Choose BMC and benefit from:

- fast, convenient online submission

- thorough peer review by experienced researchers in your field

- rapid publication on acceptance

- support for research data, including large and complex data types

- gold Open Access which fosters wider collaboration and increased citations

- maximum visibility for your research: over $100 \mathrm{M}$ website views per year

At $\mathrm{BMC}$, research is always in progress.

Learn more biomedcentral.com/submissions 